\title{
Desenvolvimento de um Sistema Computacional para Dimensionamento e Evolução de Rebanhos Bovinos 1
}

\section{Marcos Aurélio Lopes ${ }^{2}$, Paulo de Figueiredo Vieira ${ }^{3}$, Pedro Castro Neto ${ }^{4}$, Euclides Braga Malheiros ${ }^{3}$}

RESUMO - Os objetivos deste estudo foram desenvolver um sistema computacional que efetue o dimensionamento e a evolução de rebanhos bovinos e criar uma ferramenta que possibilite ao usuário efetuar simulações em um sistema de produção de carne e/ou leite. Foi utilizada a linguagem CA Clipper. As rotinas foram desenvolvidas de forma conversacional, com acesso aos diversos programas, por meio de menus auto-explicativos. O sistema desenvolvido pode auxiliar o técnico e o pecuarista no dimensionamento e na evolução de um rebanho bovino com precisão e considerável rapidez; possibilita ao usuário efetuar inúmeras simulações; e constitui -se em importante ferramenta no auxílio da tomada de decisões.

Palavras-chave: informática, planejamento do rebanho, simulação, sistema de produção

\section{Development of Software for Dimensioning and Evolution of Bovine Herds}

\begin{abstract}
The objectives of this study were to develop a software that accomplishes both the dimensioning and evolution of cattle herds and develop a tool which makes it possible for the user to perform simulations with production systems of milk and or beef. The language employed was CA Clipper. The routines have been developed in a conversational form, with an access to the several programs by means of self-explicative menus. The developed system can aid both the technician and the raiser in dimensioning and evolution of a cattle herd with precision and outstanding rapidity; it allows to the user to perform a number of simulations; and it is considered an important tool in the assistance to decision-making.
\end{abstract}

Key Words: computer science, livestock management, production system, simulation

\section{Introdução}

A bovinocultura é uma atividade de grande importância na economia do Brasil, por manter elevados percentuais do valor da produção agropecuária e também por gerar milhares de empregos diretos.

Entende-se por dimensionamento do rebanho a determinação do número de animais por categoria, visando à exploração racional da área destinada ao sistema de produção. Categoria animal é um grupo de animais de faixa etária semelhante, como fêmeas em aleitamento e fêmeas de 0 a 1 ano; ou com funções de produção semelhantes - vacas em lactação e secas. Entende-se por evolução de rebanho as modificações, em termos de variação quantitativa, ocorridas no rebanho original, que podem ocorrer em níveis de categorias ou em número de animais.

Um rebanho considerado estável é aquele que não está sofrendo modificações numéricas. Não é um rebanho estático, ao contrário, é dinâmico, pois os indivíduos que o constitui se modificam, passando de uma categoria animal para outra, ou ainda se renovam, por meio de vendas e aquisições. As vendas ocorrem devido à substituição anual de vacas, ao excesso de animais em determinada categoria, entre outros. Pode-se inferir que um rebanho estável, em um mesmo período do ano, possui em anos sucessivos sempre as mesmas categorias com os mesmos números de animais. Também as vendas e aquisições serão basicamente as mesmas e acontecerão na mesma época.

A importância de dimensionar o futuro rebanho, aquele que será o rebanho estável do sistema de produção, é o planejamento das benfeitorias: salas para ordenha, currais, silos, depósitos para feno, depósitos para ração, área para alimentação, além da mão-de-obra na propriedade. A alimentação deve ser planejada para as condições do rebanho estável, em que as áreas para pastagem, o número e tamanho dos piquetes e a área para obtenção de forragem a ser conservada deverão ser determinados em função do

\footnotetext{
1 Parte da tese do primeiro autor apresentada à UNESP/FCAV para obtenção do título de Doutor em Zootecnia.

2 Professor do Departamento de Medicina Veterinária da Universidade Federal de Lavras (UFLA), Doutorando em Zootecnia - Produção Animal (UNESP/FCAV - Jaboticabal). Bolsista PICDT - CAPES - Caixa Postal 37, Lavras - MG, 37200-000 - Telefax (035) 829-1148. E.mail: malopes@ufla.br

3 Professor da UNESP/FCAV - Jaboticabal.

4 Professor da Universidade Federal de Lavras (UFLA).
} 
rebanho estável, e não do rebanho atual, aquele que existe atualmente na propriedade.

O dimensionamento do rebanho seria função do tamanho da área e da capacidade de suporte da forrageira nela estabelecida, expressa em unidade animal (UA), que corresponderia a 1000 libras ou $450 \mathrm{~kg}$ de peso vivo (PETERSON, 1961). Este valor foi importante quando se considerou a equivalência das categorias animais, pois o número de cabeças não foi uma unidade satisfatória (ROSTON, 1985). ROSTON (1982) salientou que o tamanho do rebanho, para fins de dimensionamento das áreas de pastejo, das necessidades de forrageiras e até mesmo do concentrado, é calculado em UA.

A revolução científica e tecnológica provocada pelas novas tecnologias da informação repercute sobre o sistema produtivo como um todo, e a pecuária não poderia ficar imune, embora essa revolução tenha iniciado mais tardiamente nesse setor, quando comparada a outros setores produtivos. Devido à nova consciência que está se formando e à significativa redução dos custos na informatização, o setor primário da economia brasileira está abrindo as suas portas à revolução da informação, da mesma forma que os setores urbanos o fizeram há mais de 10 anos (ANTUNES e ANGEL, 1995).

Segundo STUTH et al. (1996), nos últimos 10 anos, a disponibilidade de sistemas computacionais para a produção animal tem crescido a uma taxa exponencial nos Estados Unidos.

No processo de informatização e modernização da bovinocultura, diversas são as aplicações e usos da informática, muitas dessas relatadas por LOPES (1997). Dentre essas, destaca-se o desenvolvimento de sistemas computacionais, visando ajudar produtores e profissionais a tomarem a decisão correta.

No Brasil, de acordo com o Guia de Softwares Agropecuários, produzido pelo GUIA AGROSOFT (1997), houve aumento de 54\% na oferta de softwares agropecuários em 1997 e 17\% em 1999 (GUIA AGROSOFT, 1999). A maioria dos softwares refere-se a gerenciamento de rebanhos bovinos. Do total de 171 cadastrados, nenhum abor- dou o assunto dimensionamento e evolução de rebanhos bovinos.

Os objetivos deste estudo foram desenvolver um sistema computacional que efetue $o$ dimensionamento e a evolução de rebanhos bovinos mantidos em sistemas de produção semi-intensivo e em regime de pastejo, visando facilitar e agilizar o processo dos cálculos, e desenvolver uma ferramenta que possibilite ao usuário efetuar simulações em um sistema de produção de leite e carne, variando os índices zootécnicos e as previsões de compra e venda.

\section{Material e Métodos}

O sistema computacional foi desenvolvido em linguagem CA Clipper, em microcomputador IBMPC compatível, em ambiente operacional MS-DOS.

Os valores de equivalência entre as categorias animais, em UA (Unidade Animal), utilizados para a realização dos cálculos para dimensionamento e evolução dos rebanhos bovinos, foram aqueles propostos por LOPES e VIEIRA (1998).

Os índices zootécnicos utilizados para dimensionar e evoluir os rebanhos foram: idade ao primeiro parto, sendo as opções 24, 30 e 36 meses; taxa de reposição anual, em porcentagem; idade para abate ou venda dos machos, sendo as opções $0,1,2$ e 3 anos; taxa de natalidade, em porcentagem; taxa de mortalidade de machos e fêmeas, por faixa etária, em porcentagem; relação vaca:touro; e relação vaca:rufião.

Para efeito de dimensionamento, o sistema permitiu a divisão do rebanho nas seguintes categorias animais: vacas em lactação; vacas "secas"; fêmeas com idade entre 0 e 1 ano; fêmeas com idade entre 1 e 2 anos; fêmeas com idade entre 2 e 3 anos; machos com idade entre 0 e 1 ano; machos com idade entre 1 e 2 anos; machos com idade entre 2 e 3 anos; touros; e rufiões.

A metodologia adotada para o dimensionamento do rebanho foi adaptada da utilizada por NEIVA (1997).

A metodologia usada para estimar a evolução do rebanho, a partir daquele existente na propriedade (ano zero), foi a seguinte: 
Rev. bras. zootec.

Categoria

Ano 1

Vaca lactação

(((vaca lactação + vaca seca $)$ - reforma anual $)+($ fêmeas entre 2 e 3 anos doano anterior - taxa de mortalidade))

$x$ taxa de natalidade

Vaca seca

(((vaca lactação + vaca seca) - reforma anual $)+$ (fêmeas entre 2 e 3 anos do ano anterior - taxa de mortalidade))

$\mathrm{x}(1$ - taxa de natalidade $)$

Vacas lactação x 50\%*

Fêmea 0 a 1 ano

Fêmea 1 a 2 anos

Fêmea 2 a 3 anos

Macho 0 a 1 ano

Macho 1 a 2 anos

Macho 2 a 3 anos

Touro

Rufião

Fêmea 0 a 1 ano do ano anterior - taxa de mortalidade ( 0 a 1 ano)

Fêmea 1 a 2 anos do ano anterior - taxa de mortalidade ( 1 a 2 anos)

Vacas lactação x 50\%*

Macho 0 a 1 ano do ano anterior - taxa de mortalidade ( 0 a 1 ano)

Macho 1 a 2 anos do ano anterior - taxa de mortalidade (1 a 2 anos)

(( (vaca lactação + vaca seca $)$ - reforma anual $)+$

(fêmeas entre 2 e 3 anos - taxa de mortalidade)) x 1 / relação vaca:touro

$((($ vaca lactação + vaca seca $)$ - reforma anual $)+$

(fêmeas entre 2 e 3 anos - taxa de mortalidade)) x 1 / relação vaca:rufião

TOTAL

SOMA DE TODAS AS CATEGORIAS

* Consideraram-se $50 \%$ de nascimentos de machos e $50 \%$ de fêmeas.

\section{Resultados e Discussão}

O sistema desenvolvido possui exigências mínimas de hardware. Um microcomputador com processador 386 e 4 MB de memória RAM, com sistema operacional DOS versão 3, ou superior, é suficiente para "hospedá-lo". Isto se constitui em importante vantagem, pois diversos produtores rurais, ao substituírem os microcomputadores de suas residências ou empresas, devido ao obsoletismo, poderiam aproveitá-los na propriedade rural.

O sistema pode ainda ser utilizado por usuários que não possuam impressora, pois os diversos relatórios gerados podem ser também gravados em arquivos, possibilitando maior uso no meio rural, onde a informática não é muito difundida (LOPES, 1997).

As rotinas foram desenvolvidas de forma conversacional, com acesso aos diversos programas por meio de menus auto-explicativos, o que permite a operação do programa por pessoas não especializadas em informática, mas apenas treinadas na operação de microcomputadores.

O Menu Principal contém as opções de Cadastros, Dimensionamento, Evolução, Rotinas Auxiliares e Relatórios. Para selecionar uma opção, o usuário deve utilizar as teclas de setas, específicas para a "navegação". À medida que se muda a opção, o menu secundário é apresentado na forma de "fichas" (Figura 1). Esse recurso facilita a operação do sistema, mostrando ao usuário todas as opções disponíveis.

A opção Cadastros permite ao usuário cadastrar senhas, para acessar o sistema, raças, alimentos, propriedades e pastagens. Ao selecionar uma das opções, é disponibilizado um menu terciário, também na forma de "fichas", contendo as opções: Inclusão, Consulta/Alteração/Exclusão e Listagem (Figura 2).

Em Dimensionamento, é disponibilizado um menu secundário, contendo as opções: Inclusão, Consulta/ Alteração/Exclusão, Listagem e Resultados. A opção

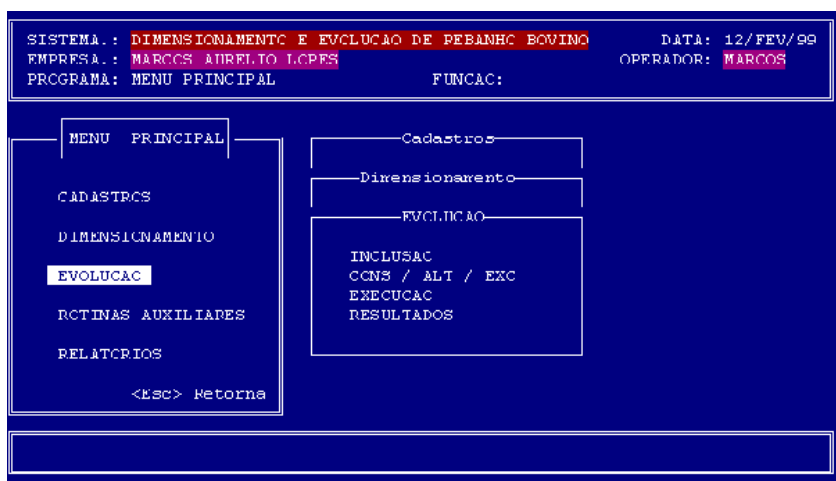

Figura 1 - Menu principal e secundário na forma de "fichas". Figure 1 - Main and secondary menu in the form of "cards". 


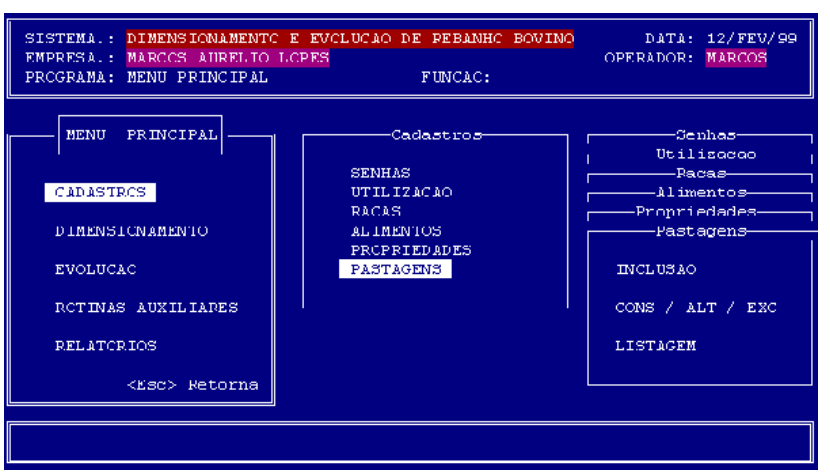

Figura 2 - Tela apresentada pelo sistema para a opção Cadastros.

Figure 2 - Screen presented for the System for the Register option.

Inclusão permite a digitação dos parâmetros a serem utilizados em um dimensionamento, assim como os índices zootécnicos da propriedade em questão (Figura 3). Consulta/Alteração/Exclusão permitem ao usuário consultar, modificar ou excluir um dimensionamento já realizado. A opção Listagem permite ao usuário a impressão dos dados de um dimensionamento e a opção Resultados, visualizar, no monitor, a composição do rebanho dimensionado, em número de cabeças e UA.

Em Evolução, é disponibilizado um menu secundário contendo as opções de Inclusão, Consulta/ Alteração/Exclusão, Execução e Resultados. A inclusão de uma evolução está atrelada a um dimensionamento já cadastrado.

A opção Rotinas Auxiliares visa auxiliar na manutenção periódica do sistema, como gerar e retornar cópias de segurança, assim como restabelecer os arquivos de índice do sistema.

Em Relatórios, estão disponíveis as seguintes opções: Planilhas, Dimensionamento, Evolução, Previsão de Compras, Previsão de vendas, Previsão de mortes, Parâmetros da evolução, Etiquetas, Dimensionamentos por propriedade, Evoluções por dimensionamento e por propriedade e Cadastro da propriedade. As planilhas visam facilitar a coleta de dados no campo.

Ao optar por Cadastros/Raças, é disponibilizado um menu terciário, contendo as opções Inclusão, Consulta/Alteração/Exclusão e Listagem.

Em Inclusão, o usuário deve digitar o nome e o porte da raça, classificado em pequeno, médio ou grande (Figura 4). Para dimensionar e estimar a evolução de um rebanho, o sistema utiliza os valores de equivalência entre as categorias animais específicas para cada porte de raça. Tal fato é inovação nos cálculos de dimensionamento de rebanhos, mesmo nos procedimentos não-automatizados (manual). $\mathrm{O}$ campo código da raça, a ser cadastrado, é preenchido automaticamente pelo sistema.

Ao optar por Cadastros/Alimentos, é disponibilizado um menu terciário, contendo as opções: Inclusão, Consulta/Alteração/Exclusão e Listagem.

Em Inclusão, o usuário deve digitar o nome comum e científico, a forma de utilização, a capacidade de suporte no período chuvoso e seco, a produtividade e o consumo.

Os alimentos deverão ser classificados de acordo

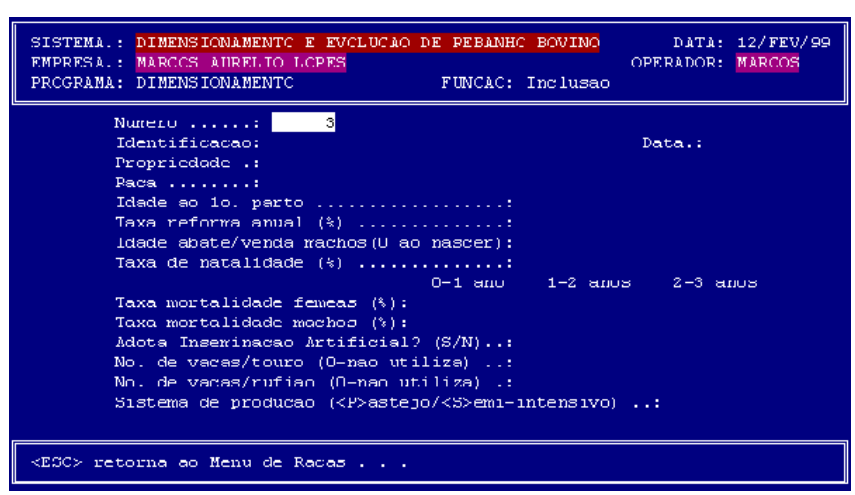

Figura 3 - Tela apresentada pelo sistema para a função Inclusão da opção Dimensionamento.

Figure 3 - Screen presented for the system for the function Inclusion of the Dimensioning option.

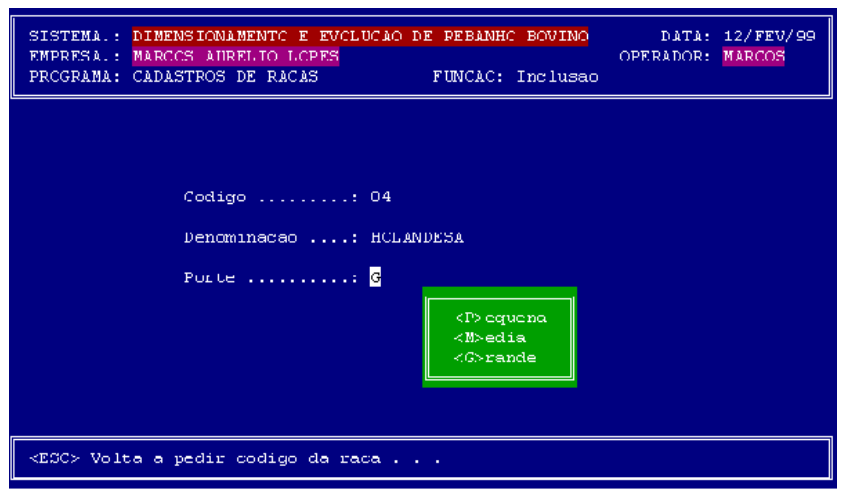

Figura 4 - Tela apresentada pelo sistema para a opção Cadastro de Raças.

Figure 4 - Screen presented for the system for the Register of Breeds option. 
Rev. bras. zootec.

com sua forma de utilização em capineira, feno, pastejo, silagem e outros (Figura 5), sendo esse último normalmente utilizado para alimentos adquiridos de outras empresas e que não se enquadram nas classificações anteriores.

Se o alimento for classificado como pastagem, o usuário deverá informar a capacidade de suporte nos períodos chuvoso e seco.

Para os classificados como capineiras, fenos e silagens, deverá ser fornecida a produtividade anual esperada, em toneladas por hectare, assim como o consumo, em $\mathrm{kg} / \mathrm{UA} / \mathrm{dia}$, considerando que somente esse alimento será oferecido como volumoso (Figura 6).

Ao optar por Cadastros/Propriedade, é disponibilizado um menu terciário, contendo as opções Inclusão, Consulta/Alteração/Exclusão e Listagem. Em Inclusão, o usuário deverá digitar os dados cadastrais da propriedade.

Ao optar por Cadastros/Pastagens, é disponibilizado um menu terciário, contendo as opções Inclusão, Consulta/Alteração/Exclusão e Listagem.

Em Inclusão, inicialmente, o usuário deve indicar a propriedade para a qual está incluindo a pastagem. Para isso, deverá fornecer o código da propriedade desejada ou teclar <enter> para acionar a rotina de busca. Após identificada a propriedade, o sistema apresenta alguns dados cadastrais da propriedade, para conferência do usuário. Para cadastrar uma pastagem em determinada propriedade, o usuário deverá digitar o código do alimento ou utilizar a rotina de busca, caso não se lembre do código, bem como a

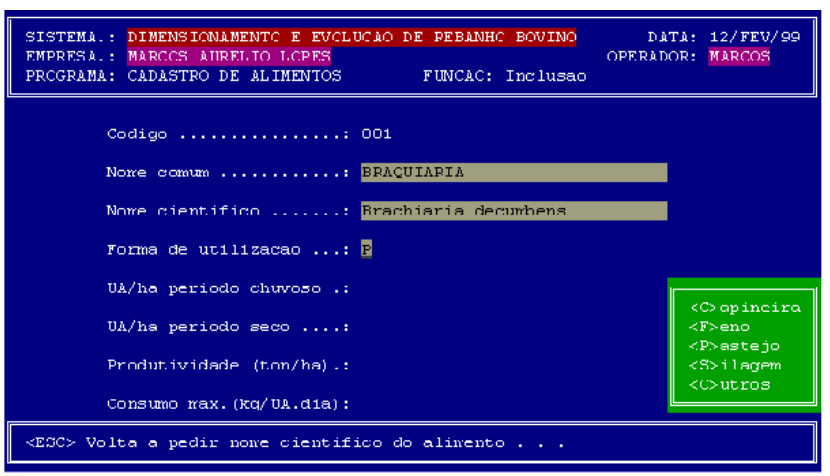

Figura 5 - Tela apresentada pelo sistema para a opção Cadastro de Alimento.

Figure 5 - Screen presented for the system for the Register of Feed option. área ocupada pela forrageira. O somatório de todas as áreas ocupadas pelas diversas forrageiras é apresentado na tela do monitor e representa a área destinada à bovinocultura da propriedade.

Para realizar o dimensionamento, o usuário deverá identificar o dimensionamento e a propriedade para a qual esse é válido, assim como efetuar a digitação dos parâmetros e dos índices zootécnicos a serem utilizados no dimensionamento do rebanho bovino da propriedade em questão. No que diz respeito à idade ao primeiro parto, o sistema possui três opções: 24,30 e 36 meses; em função desse índice, utiliza o valor específico de equivalente entre as categorias animais, o que também é inovação nos cálculos de dimensionamento de rebanhos, mesmo nos procedimentos não-automatizados (manual). Uma tela de inclusão de dimensionamento totalmente preenchida pode ser observada na Figura 7.

Acionando a opção Resultados, o usuário visualiza a composição do rebanho dimensionado, em número de cabeças e UA (Figura 8).

O sistema realiza o dimensionamento de rebanhos bovinos mantidos em sistemas de produção em regime de pastejo e semi-intensivo. Em se tratando de semi-intensivo, é solicitada a forma de suplementação alimentar a ser adotada, em que o usuário deve informar a duração do período de suplementação, em dias, e até três opções de alimentos diferentes, com suas respectivas percentagens de utilização.

Assim, o rebanho é dimensionado em função da capacidade de suporte da forrageira apenas no período

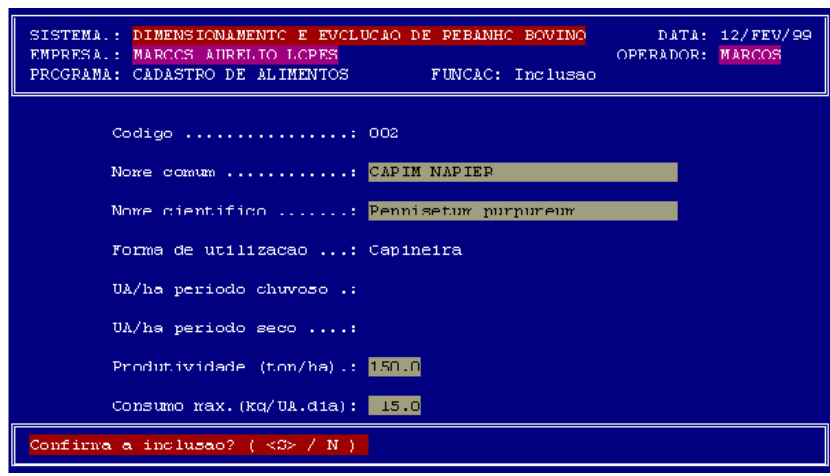

Figura 6 - Tela apresentada pelo sistema ao se cadastrar uma capineira.

Figure 6 - Screen presented for the system to in the register of a stock pile. 


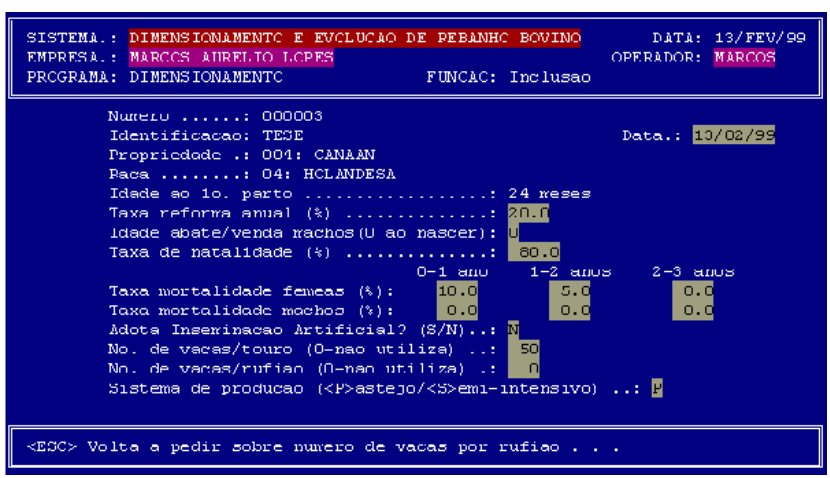

Figura 7 - Tela apresentada pelo sistema para a opção Inclusão de Dimensionamento Concluída.

Figure 7 - Screen presented for the system for the Inclusion of the Dimensioning Concluded option.

chuvoso, pois no período seco os animais recebem alimentação suplementar. Para uma propriedade hipotética com 100 ha cultivados com uma forrageira cuja capacidade de suporte é de 2 e $1 \mathrm{UA} / \mathrm{ha}$, no período chuvoso e seco, respectivamente, o rebanho dimensionado é apresentado na Figura 9. Observe que o sistema dimensionou o rebanho considerando ter, a propriedade, uma capacidade de suporte igual a $200 \mathrm{UA}$ (100 ha x 2 UA). Caso essa propriedade não fizesse uso da suplementação, a composição do rebanho seria a

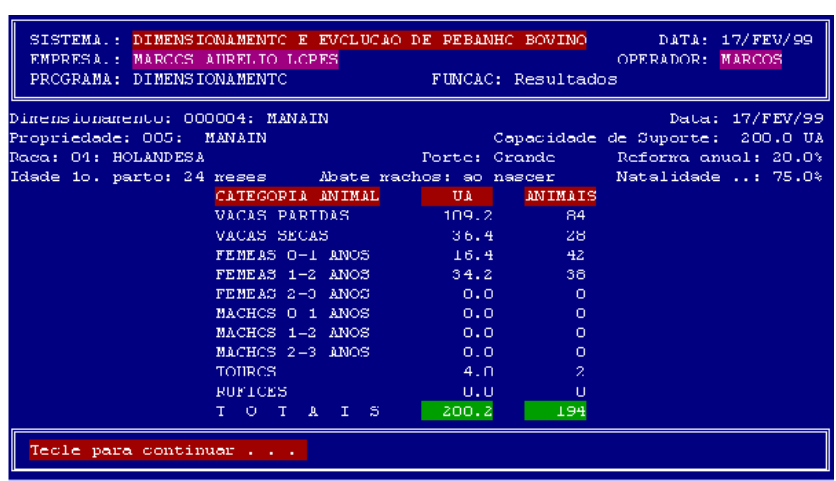

Figura 9 - Tela apresentada pelo Sistema mostrando a composição do rebanho para uma propriedade com suplementação alimentar na "seca".

Figure 9 - Screen presented for the System showing the composition of the herd for a property with feed supplementation in "dry season ".

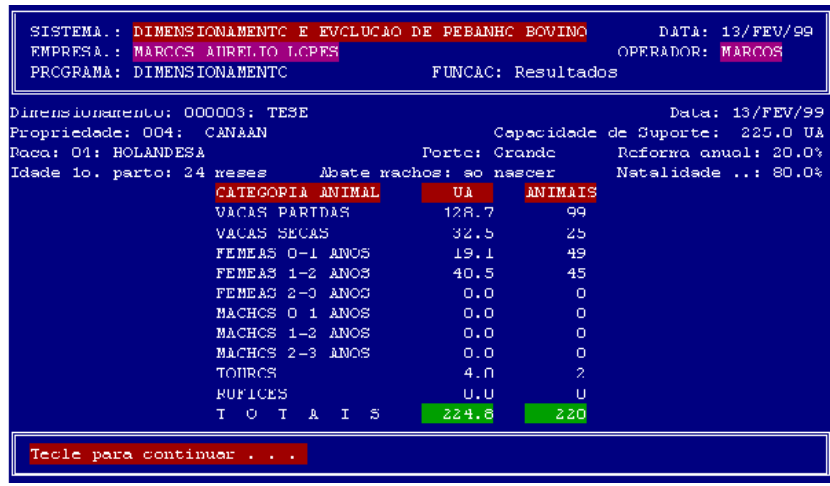

Figura 8 - Tela apresentada pelo Sistema para a opção Resultado de um Dimensionamento.

Figure 8 - Screen presented for the System for the Resulted Dimensioning option.

apresentada na Figura 10. Nessa situação, o sistema dimensionou orebanho considerando ter, a propriedade, uma capacidade de suporte igual a $150 \mathrm{UA}$, ou seja $((100$ ha $\times 2$ UA $)+(100$ ha $\times 1$ UA $)) / 2$. Tomando-se como referencial o número total de animais, o rebanho suplementado é 33,8\% maior que o não-suplementado.

O sistema calcula a estimativa de alimentos a serem utilizados para a suplementação do rebanho, bem como a área que deverá ser cultivada, sendo, para o exemplo apresentado, $1.201,1 \mathrm{t}$ e 30 ha,

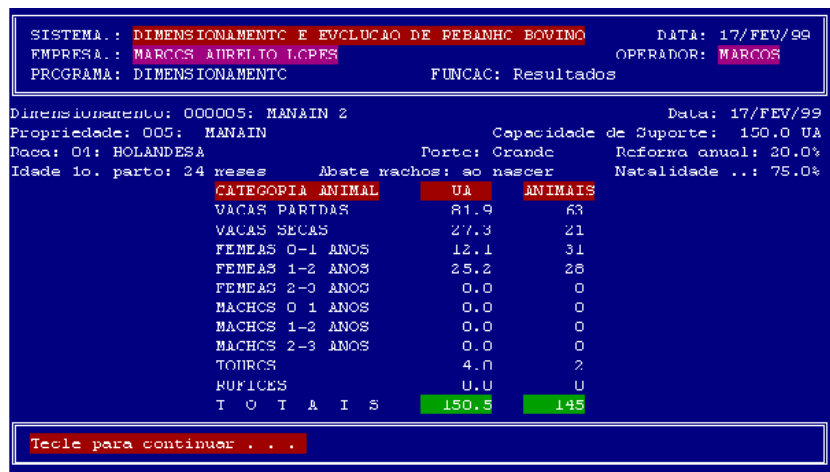

Figura 10 - Tela apresentada pelo Sistema mostrando a composição do rebanho para uma propriedade sem suplementação alimentar na "seca".

Figure 10 - Screen presented for the System showing the composition of the herd for a property without feed supplementation in the " dry season". 
Rev. bras. zootec.

respectivamente (Figura 11).

Para realizar a evolução de um rebanho, o usuário deverá identificar a evolução e informar ao sistema qual o dimensionamento base, $\mathrm{o}$ ano a ser considerado como inicial, bem como o rebanho atual da propriedade, ou seja, o número de animais, por categoria, existente

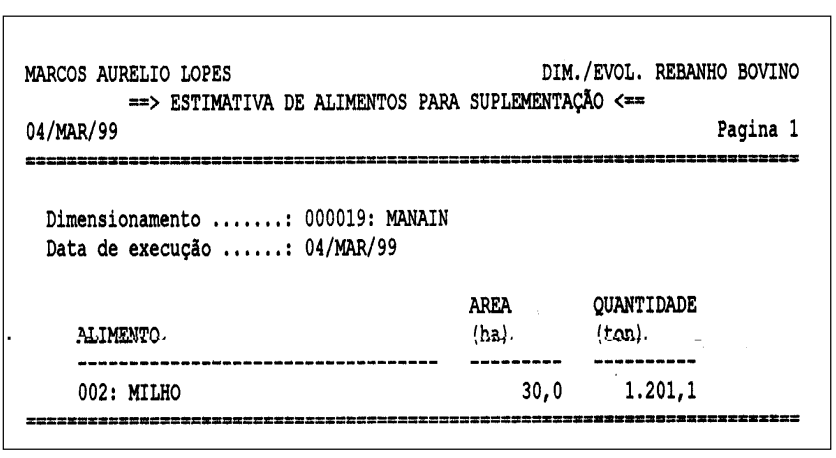

Figura 11 - Relatório da Estimativa de Alimentos para Suplementação a ser utilizada para o rebanho.

Figure 11 - Report of the Estimate of Feeds Supplementation to be used for the herd.

primeiro parto e idade esperada de abate dos machos) podem ser feitas a cada ano (Figura 13), pois esses índices podem ainda apresentar variação ao longo do tempo, uma vez que se espera sempre o aperfeiçoamento tecnológico da atividade. Nessa situação, o sistema assume como rebanho atual o rebanho do ano anterior à alteração dos índices zootécnicos.

Alterações nas previsões de compras e vendas também podem ser realizadas (Figura 13). Se o usuário optar por não alterar as previsões de vendas, o Sistema venderá apenas o número de vacas referente à taxa de reforma anual e machos acima da idade de abate. Essa versatilidade permite ao usuário fazer inúmeras simulações visando à exploração eficiente do sistema de produção.

Pode-se observar que, no ano 2000 (Figura 13), na coluna referente à compra, o Sistema automaticamente informa que deve ser adquirido um touro, pois a relação touro:vaca não foi atendida. Nesse mesmo ano, na coluna de vendas, é mostrada ao usuário a quantidade matrizes e machos disponíveis para a venda. Tais quantidades referem-se à taxa de reforma anual e machos com idade de abate, respectivamente. Esses números sãoúteis, ao técnico e produtor, no planejamento do sistema de produção e na tomada de decisão. na propriedade (Figura 12). A partir desse rebanho, o sistema faz a evolução.

Acionando a opção Execução, o sistema realiza, sob a supervisão do usuário, a evolução do rebanho ano a ano.

Alterações nos índices zootécnicos (taxa de natalidade, taxa de mortalidade, reforma anual, idade ao

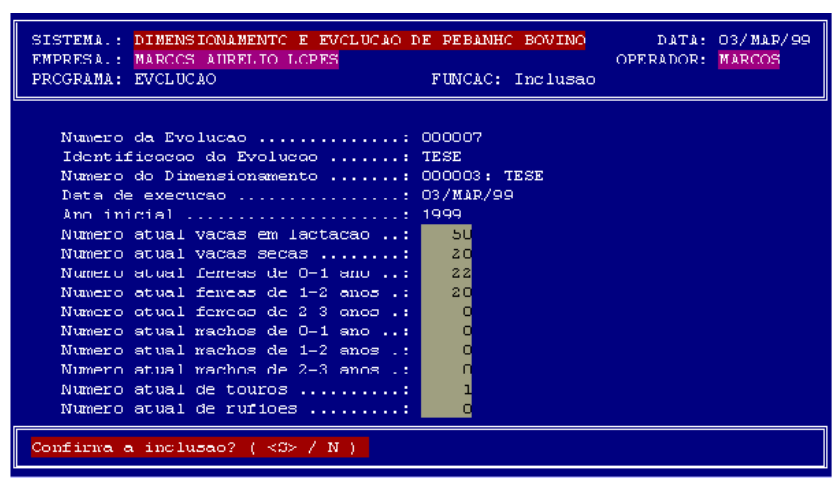

Figura 12 - Tela apresentada pelo sistema mostrando a Inclusão de uma Evolução.

Figure 12 - Screen presented for the system showing the Inclusion of an Evolution.

Uma vez estabilizado o rebanho, o sistema informa ao usuário por intermédio de mensagem na tela (Figura 14) e sinal sonoro.

Em Resultados, a partir da identificação da evolução desejada, o usuário pode visualizar a

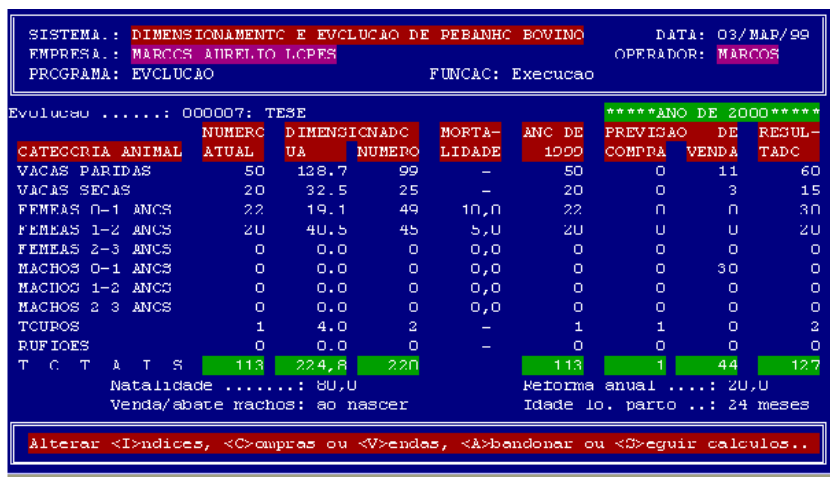

Figura 13 - Tela apresentada pelo sistema mostrando a Execução da Evolução de um Rebanho.

Figure 13 - Screen presented for the system showing the Execution of the Evolution of a Herd. 
composição do rebanho ano a ano até a estabilização, além da composição do rebanho atual e do ideal (Figuras 15 a 18).

Visando melhor e mais detalhada análise, o sistema emite diversos relatórios, gravando-os em meio magnético ou imprimindo-os diretamente em impressora. Esse recurso possibilita melhor armazenamento da documentação gerada e aumenta as possibilidades de transmissão dos dados por intermédio de facsimile, fax modem e internet.

O relatório Dimensionamento retrata o resultado de um dimensionamento, mostrando a composição do rebanho ideal (número de animais em cada categoria), ou seja, a situação ótima para uma exploração racional do sistema de produção e o Evolução, o resultado da evolução de um rebanho, a partir da composição

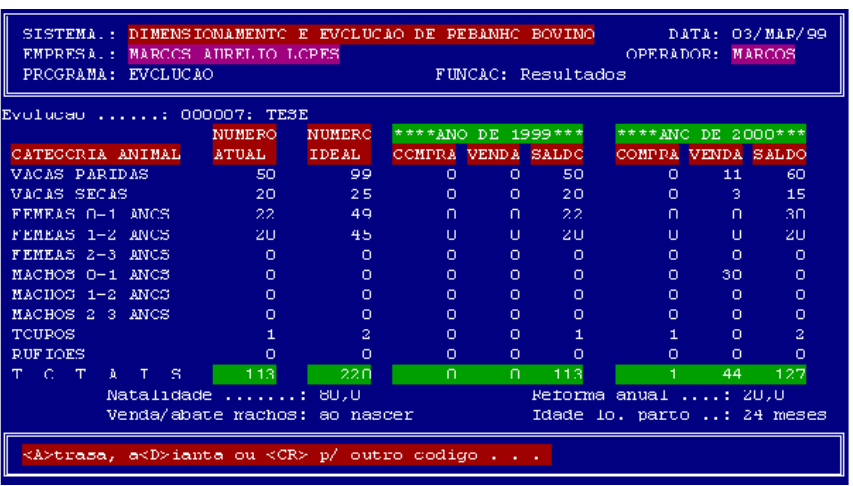

Figura 15 - Tela apresentada pelo sistema mostrando os resultados parciais da Execução da Evolução de um Rebanho.

Figure 15 - Screen presented for the system showing the partial results of the Execution of the Evolution of a Herd.

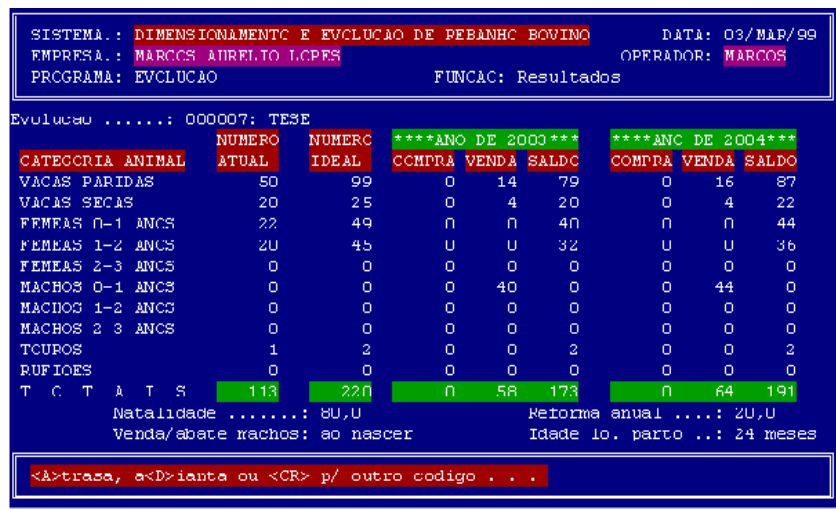

Figura 17 - Tela apresentada pelo sistema mostrando os resultados parciais da Execução da Evolução de um Rebanho.

Figure 17 - Screen presented for the system showing the partial results of the Execution of the Evolution of a Herd.

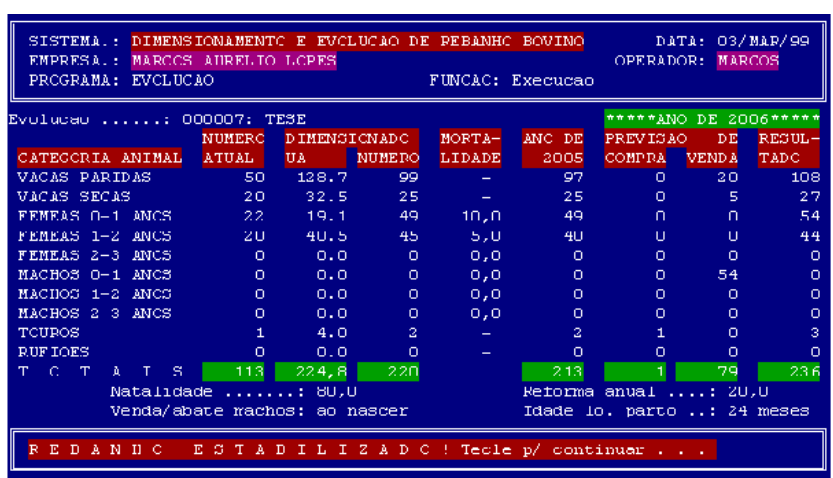

Figura 14 - Tela apresentada pelo sistema mostrando o final da Execução da Evolução de um Rebanho.

Figure 14 - Screen presented for the system showing the end of the Execution of the Evolution of a Herd.

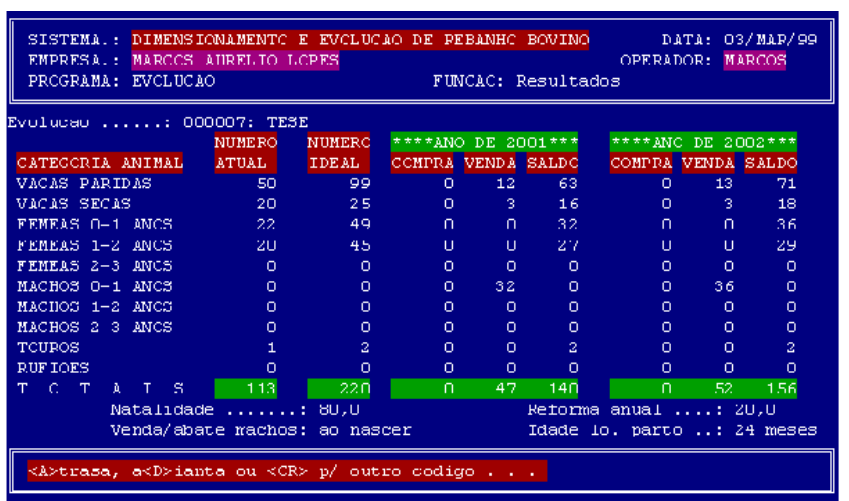

Figura 16 - Tela apresentada pelo sistema mostrando os resultados parciais da Execução da Evolução de um Rebanho.

Figure 16 - Screen presented for the system showing the partial results of the Execution of the Evolution of a Herd.

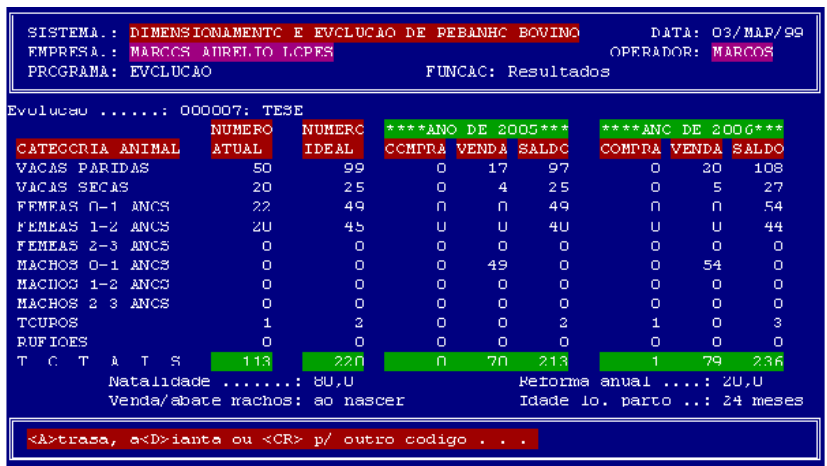

Figura 18 - Tela apresentada pelo sistema mostrando os resultados parciais da Execução da Evolução de um Rebanho.

Figure 18 - Screen presented for the system showing the partial results of the Execution of the Evolution of a Herd. 
Rev. bras. zootec.

atual até a estabilização, mostrando a composição do rebanho a cada ano.

Previsão de compras e vendas informa o número previsto de animais a serem adquiridos e vendidos, respectivamente, em cada categoria, até a estabilização do rebanho. Previsão de mortes informa o número previsto de mortes, em cada categoria, em função das taxas de mortalidades adotadas, até a estabilização do rebanho. Parâmetros da evolução mostram os parâmetros zootécnicos utilizados em cada ano da evolução do rebanho até a sua estabilização. Em Dimensionamentos por propriedade, são impressas as informações dos dimensionamentos executados para uma determinada propriedade; em Evoluções por dimensionamento, as informações das evoluções executadas para determinado dimensionamento; e em Evoluções por propriedade, as informações das evoluções executadas para uma determinada propriedade. O relatório Cadastro da propriedade permite a impressão dos dados cadastrais de uma propriedade, assim como listar as pastagens cadastradas para essa propriedade. Tais relatórios constituem importantes ferramentas para análise do sistema de produção e auxiliam o técnico e o pecuarista na tomada de decisões.

Para facilitar a coleta de informações no campo, visando ao levantamento de dados, são emitidas planilhas para raças, alimentos, propriedades, pastagens, dimensionamento, suplementação e situação atual do rebanho.

\section{Conclusões}

O Sistema desenvolvido pode auxiliar o técnico e o pecuarista no dimensionamento e evolução de um rebanho bovino, leiteiro ou de corte, mantidos em sistemas de produção em regime de pastejo ou em semiconfinamento, com precisão e considerável rapidez.

O sistema desenvolvido possibilita ao usuário efetuar inúmeras simulações da composição de rebanho variando os alimentos, as raças e os índices zootécnicos a serem adotados na propriedade, bem como as possibilidades de aquisições e vendas de animais.

O sistema desenvolvido constitui uma importante ferramenta no auxílio da tomada de decisões.

\section{Referências Bibliográficas}

ANTUNES, L.M., ANGEL, A. 1995. A informática na agropecuária. Canoas: Gráfica e Editora Interclubes. 157p.

GUIA AGROSOFT 97. 1997. 147 opções prontas para uso. Revista Agrosoft., (1):3-15.

GUIA AGROSOFT 99. 1999. Revista Agrosoft., (6):4-25.

LOPES, M.A. 1997. Informática aplicada à bovinocultura. Jaboticabal: FUNEP. 82p.

LOPES, M.A., VIEIRA, P. de F. Proposta de novos valores de equivalência entre as categorias animais a serem utilizados para dimensionar rebanhos bovinos. In: REUNIÃO ANUAL DA SOCIEDADE BRASILEIRA DE ZOOTECNIA, 35, Botucatu, 1998. Anais... Botucatu, 1998.

NEIVA, R.S. 1997. Bovinocultura de leite. Lavras: UFLA/FAEPE, 540 .

PETERSON, R.A. 1961. Carga animal e intensidade de pastoreio. In: SÃO PAULO. Secretaria da Agricultura. Fundamentos de manejo de pastagens. São Paulo: Instituto de Zootecnia, p.109-12.

ROSTON, A.J. Planejamento de exploração leiteira. 1985. In Utilização de técnicas modernas na exploração leiteira. Campinas: Fundação Cargill. p.1-56.

ROSTON, A.J. Bases para o planejamento das explorações pecuárias: bovinos. In: SIMPÓSIO SOBRE PRODUÇÃO ANIMAL, 1982, Piracicaba. Anais... Piracicaba, 1982, p.1-52.

Recebido em: 12/11/99

Aceito em: 31/02/00 